\title{
NORMATIVIDAD EPISTÉMICA Y ESTRUCTURA HEURÍSTICA DEL RAZONAMIENTO*
}

\author{
ÁngELES ERAÑa Lagos \\ Instituto de Investigaciones Filosóficas \\ Universidad Nacional Autónoma de México \\ mael@filosoficas.unam.mx
}

RESUMEN: En años recientes se han diseñado múltiples experimentos que muestran cómo el razonamiento humano tiende a quebrantar lo que usualmente se consideran los principios normativos de razonamiento, a saber, los principios de la teoría estándar de la probabilidad y de la lógica clásica. Estos supuestos quebrantos han sido interpretados como muestra de la irracionalidad humana. Una noción de norma del razonamiento diferente de la subyacente en dicha interpretación me permite afirmar que razonar correctamente implica razonar de acuerdo con reglas diseñadas para resolver una clase limitada de problemas en el marco de un dominio específico y que pueden no ser formulados en términos de principios generales. Esta idea me lleva a sostener que la estructura heurística de nuestro razonamiento apunta a la manera como somos racionales.

PALABRAS CLAVE: racionalidad, psicología cognoscitiva, dependencia epistémica, procedimientos heurísticos

SUMMARY: Much research in the last decades has demonstrated that human reasoning tends to violate what have usually been regarded as the normative principles of reasoning - e.g. the principles of standard theory of probability or classical logic. These supposed violations have been interpreted as indicating systematic irrationalities in human cognition. A notion of a reasoning norm different from that underlying such an interpretation allows me to assert that correct reasoning implies reasoning in accordance with rules designed to solve a limited class of problems in a specific domain of knowledge and which are not susceptible to being formulated in terms of general principles. This contention leads me to sustain that the heuristic structure of our reasoning signals the way in which we are rational.

KEY WORDS: rationality, cognitive psychology, epistemic dependency, heuristic procedures

*Agradezco a Sergio Martínez, Axel Barceló y Lorena García sus útiles comentarios y revisiones a versiones previas de este trabajo. 


\section{Introducción}

En años recientes se han diseñado múltiples experimentos para diagnosticar el tipo de procedimiento cognoscitivo que los seres humanos utilizamos en nuestros razonamientos cotidianos. La conducta observada tiende a la violación de los principios del razonamiento correcto, a saber, los principios básicos de la teoría estándar de la probabilidad y de la lógica clásica. Esta característica general de los resultados obtenidos ha suscitado una discusión importante en torno a la racionalidad; en particular, la estructura del razonamiento humano ha pasado a ocupar el centro de la discusión.

En este artículo analizaré dos interpretaciones de los resultados experimentales. La primera ha sido favorecida por los psicólogos que diseñaron los experimentos, y ha dado lugar a la "tesis de irracionalidad", de acuerdo con la cual los errores de razonamiento deben atribuirse al uso de reglas heurísticas, esto es, a la utilización de sistemas de instrucciones que nos permiten solucionar un problema, no de manera exacta ni en todos los casos, pero sí de manera que no sea necesaria una computación excesiva desde el punto de vista de los recursos cognoscitivos que tenemos disponibles. La idea central de estos psicólogos es que la evidencia de los experimentos es suficiente para afirmar que el razonamiento humano se guía sistemáticamente por reglas heurísticas y, puesto que estas reglas son diferentes de las normas de razonamiento, es posible concluir que los seres humanos somos irracionales.

La segunda interpretación se sustenta en la llamada "tesis de racionalidad", según la cual los seres humanos tenemos una capacidad o habilidad subyacente para razonar de acuerdo con las normas de razonamiento y, en esa medida, los errores observados deben atribuirse a factores ajenos a nuestra competencia racional. Esta posición critica severamente la conclusión que sostienen los psicólogos, e implícitamente rechaza la idea de que nuestro razonamiento tiene una estructura heurística. Un número importante de filósofos, entre quienes destaca Jonathan Cohen, ha dado argumentos a favor de esta postura. 
Finalmente, en coincidencia con Gerd Gigerenzer (2000) y Sergio Martínez (2002), afirmo que la definición misma de "buen razonamiento" conforme a la cual fueron construidas dichas interpretaciones es incorrecta. Esto me llevará a cuestionar la noción de racionalidad subyacente en mucha de la epistemología contemporánea y, en particular, en las dos tesis de las que me ocuparé en el presente artículo. La posición que defiendo sostiene que la forma en que se presenta la información en los problemas del razonamiento a los que se enfrentan los sujetos encuestados y el contenido específico del material, objeto del razonamiento, son parte de un contexto más amplio en el que las normas del razonamiento se establecen, se desarrollan y se validan. Mi tesis es que la estructura heurística del razonamiento apunta a la manera como somos racionales; para defenderla mostraré que la evidencia obtenida por los psicólogos nos permite concluir que "la gente usa heurísticas en vez de teoría de la probabilidad, pero no... que sus juicios sean generalmente pobres" (Lopes 1991, p. 75) ni que los seres humanos seamos irracionales.

\section{Sesgos e irracionalidad}

La interpretación de los experimentos mencionados en la introducción, y que está sustentada en la tesis de racionalidad, llega a conclusiones opuestas a las que sacan los psicólogos cognoscitivos a partir de las siguientes premisas compartidas: 1) "ser racional" significa razonar, la mayor parte del tiempo, de acuerdo con los principios de razonamiento; 2) dichos principios están basados en las reglas de la lógica y del cálculo de probabilidades, ${ }^{1}$ entre otros sistemas formales, y 3) una descripción

${ }^{1}$ En términos generales, la bibliografía psicológica sobre "sesgos y heurísticas" tiende a identificar las reglas normativas del razonamiento con las reglas que provienen del cálculo proposicional. Esto, sin embargo, no tiene por qué implicar que los supuestos principios normativos del razonamiento no se refieren a los principios subyacentes en las reglas de otras lógicas más recientemente desarrolladas (deónticas, libres, borrosas, etc.). Si esto último fuese el caso, podría argumentarse que, si bien las reglas de la "lógica clásica" no son suficientes para modelar todos nuestros razonamientos, el surgimiento de nuevas lógicas es alentador con respecto a dicho fin. Desde mi punto de 
correcta del razonamiento real de los seres humanos nos permite dar cuenta de la constitución de nuestra competencia racional.

Dos de los supuestos subyacentes en estas premisas son los siguientes: i) el análisis de nuestros conceptos epistémicoevaluativos hace explícitos, en una teoría del razonamiento, los principios que rigen nuestro proceder racional y establece las normas que prescriben cómo deben relacionarse los contenidos de nuestras creencias entre sí, con otras actitudes proposicionales y con nuestra conducta; y ii) los seres humanos tenemos ciertas creencias preteóricas que constituyen las premisas más fundamentales de nuestras deducciones o construcciones teóricas (Cohen 1986). Estas creencias, también llamadas "intuiciones", se originan en un sistema de reglas tácitamente conocido y universalmente compartido para hacer juicios con respecto a temas relevantes; el conocimiento de dicho sistema constituye nuestra competencia racional. Nótese que en estos supuestos subyace la distinción competencia-ejecución, donde, por un lado, la primera suele identificarse con un mecanismo que subyace en la habilidad de los seres humanos para razonar que los dota con una racionalidad perfecta (o casi perfecta) y, por el otro, la ejecución se entiende como un conjunto de herramientas que activan dicho mecanismo (Sober 1978, p. 177). Existen distintas formas de entender la "competencia" de razonamiento; aunque, en términos generales, refiere a la capacidad humana para razonar y al conocimiento tácito de los principios de razonamiento; la ejecución, por su parte, es la manera concreta de implementar dichos principios, que puede ser influida por factores de interferencia tales como el olvido o la distracción. ${ }^{2}$

vista, esta idea es problemática: es posible afirmar que hay razonamientos que responden a reglas cuya formulación depende del contenido de un problema específico y, por tanto, la estructura de nuestro razonamiento y lo que significa "ser racional" tiene aspectos que probablemente no puedan ser capturados por las reglas propuestas en los múltiples sistemas lógicos formales que existen. No me adentraré en esta discusión; sólo quiero establecer que la aceptación de esta última idea no implica la negación de la importancia del desarrollo de las lógicas mencionadas para entender la estructura de nuestro razonamiento.

${ }^{2}$ Esta distinción proviene de la propuesta por Chomsky, según la cual una explicación plausible de la conducta lingüística de los seres humanos — de la sorprendente capacidad de los niños para aprender un lenguaje de manera ex- 
Si aceptamos estos dos supuestos y si, además, aceptamos que nuestras nociones intuitivas de aceptabilidad epistémica concuerdan con los principios emanados de las reglas de la lógica, del cálculo de probabilidades, o de otros sistemas formales, entonces los principios del razonamiento que están basados en dichas reglas deben ser vistos como principios normativos del razonamiento, esto es, como principios de acuerdo con los cuales debemos razonar (Stein 1996, p. 4). Así, la primera premisa antes mencionada puede reformularse de la siguiente manera:

\section{$\left.1^{\prime}\right)$ "ser racional" significa tener una competencia constituida por los principios normativos del razonamiento.}

Si los principios de razonamiento provienen de nuestras nociones intuitivas de aceptabilidad epistémica (en el sentido de que son el resultado del análisis de dichos conceptos), y éstas de

pedita, de nuestra capacidad para generar múltiples oraciones nuevas, etc.supone que el conocimiento lingüístico es una habilidad o capacidad, o un conjunto de disposiciones previamente "cableadas" en nuestro sistema cognoscitivo. La competencia lingüística se ha entendido de diversas maneras, las más desarrolladas son las siguientes: a) como una idealización, esto es, como una manera de explicar el comportamiento lingüístico en condiciones ideales haciendo abstracción de los factores de interferencia; b) como un mecanismo que subyace en la condición lingüística de los seres humanos; esta versión presupone la existencia de un órgano mental que incorpora nuestro conocimiento del lenguaje y es responsable de nuestras capacidades lingüísticas, y c) como el conocimiento del lenguaje. En teoría del razonamiento, la distinción se utiliza para explicar nuestra conducta cognoscitiva a partir de las diferencias que existen entre aquellas inferencias que se hacen de acuerdo con la competencia y aquellas que resultan de factores de interferencia y que pueden constituir errores de ejecución. La competencia de razonamiento ha sido concebida, al menos, de las siguientes dos maneras: a) como el conocimiento subyacente de los principios del razonamiento correcto, y b) como una habilidad para razonar correctamente en circunstancias adecuadas. Estas dos versiones no son incompatibles, ya que no parece haber (como en la lingüística) una diferencia entre el conocimiento de los principios y los mecanismos de razonamiento; esto es, no hay evidencia suficiente para afirmar que existen mecanismos específicos de razonamiento que no son parte de nuestro conocimiento de los principios mencionados. Para una discusión detallada de la distinción, veánse Stein 1996, Chomsky 1986 y Macnamara 1986. 
nuestra competencia racional, ${ }^{3}$ entonces podemos aceptar que los principios normativos del razonamiento provienen de nuestra competencia y, por tanto, ésta debe estar acorde con ellos. Stein formula muy claramente la estructura del argumento en que se sostiene $1^{\prime}$ :

1. Los principios normativos del razonamiento provienen de nuestras intuiciones de lo que constituye un buen razonamiento.

2. Nuestras intuiciones de lo que constituye un buen razonamiento provienen de nuestra competencia racional.

3. Si 1 y 2, entonces los principios normativos del razonamiento provienen de nuestra competencia racional.

4. Si 3, entonces la competencia racional debe estar acorde con los principios normativos del razonamiento (Stein 1996, pp. 137-138). ${ }^{4}$

${ }^{3}$ Macnamara enuncia muy claramente esta idea, aunque no se refiere a la competencia de razonamiento, sino a la competencia lógica: "En consonancia con el razonamiento de Chomsky, si podemos ubicar el origen de las formas particulares de inferencia que sean satisfactorias para la gente en los recursos básicos de la mente, entonces estaremos autorizados a afirmar que hemos logrado una adecuación explicativa con respecto a dichas formas de inferencia. En otras palabras, nuestra explicación estaría basada entonces en los recursos naturales de la mente - lo cual, por cierto, no es lo mismo que dar una razón para juzgar que esas formas de inferencia son válidas." (Macnamara 1986, p. 32; la traducción es mía).

${ }^{4}$ Macnamara sostiene una versión de este argumento para la competencia lógica: "El conjunto de inferencias válidas es infinito. El subconjunto de aquellas inferencias que cualquier individuo formulará o encontrará en el razonamiento de otros es demasiado grande y azaroso como para que sea posible memorizarlo. De esto se sigue que debemos tener acceso a un conjunto de reglas que puedan combinarse de varias maneras para generar un conjunto infinito de inferencias. Así, el fundamento que buscan los lógicos para la(s) lógica(s) — la(s) lógica(s) ideal(es) - , debe ser psicológicamente real en el sentido de que ejemplifique de alguna manera en la mente. Además, las mejores lógicas encontradas en los libros de lógica actuales proporcionan las mejores guías existentes para la competencia lógica." (Macnamara 1986, p. 3; la traducción es mía). En el mismo texto dice: "Una lógica que es verdadera para la intuición en cierta área constituye una teoría de la competencia para el área correspondiente de la psicología cognoscitiva." (Macnamara 1986, p. 22). 
La segunda premisa compartida por los defensores de las tesis de racionalidad e irracionalidad - los principios del razonamiento están basados en las reglas de la lógica y del cálculo de probabilidades - se apoya en la idea de que aun si estas reglas no prescriben maneras de relacionar creencias - son reglas de argumentación, no de razonamiento-,${ }^{5}$ los principios que emanan de ellas son la base sobre la cual se establecen los principios que determinan las relaciones que debe haber entre las creencias de cualquier sujeto, si éste ha de ser considerado racional. Esto es, desde este punto de vista, los principios de revisión de creencias (y algunas normas del razonamiento) se refieren a normas de argumentación tales como los principios de implicación: el modus ponens, por ejemplo, no dice nada acerca de la revisión de nuestras creencias, pero muchos de los principios de revisión de creencias se refieren al principio de argumentación expresado en la regla en cuestión.

La tercera premisa - una descripción correcta del razonamiento real de los seres humanos nos permite dar cuenta de la constitución de su competencia de razonamiento - se sostiene en la idea de que la habilidad real de los sujetos para razonar es indicativa de las reglas que comúnmente guían su razonamiento o que constituyen su competencia racional. Así, si una descripción correcta de nuestro razonamiento nos permite aseverar que la mejor explicación de los errores cometidos en los experimentos es aquella que los considera fallos en la ejecución, tenemos buenas razones para pensar que nuestra competencia de razonamiento está constituida por los principios normativos del razonamiento. Si, por otro lado, estos errores no pueden explicarse de esta manera, entonces tendremos que aceptar que nuestra competencia se conforma con principios diferentes de los mencionados y, por tanto, que somos irracionales.

${ }^{5}$ Harman dice: "Evidentemente, el argumento o la prueba no es el mismo tipo de cosa que el razonamiento [...]. Hay una clara diferencia de categoría. Las reglas de argumentación son principios de implicación que dicen que las proposiciones (o las aseveraciones) de tal y cual tipo implican a las proposiciones (o las aseveraciones) de tal y cual otro tipo" (Harman 1988, p. 3; la traducción es mía). 
La diferencia más importante entre las tesis de racionalidad e irracionalidad radica en la explicación de los errores observados en los experimentos. Los defensores de ambas tesis coinciden en que cualquier desacuerdo que pueda haber entre el razonamiento real de los sujetos y los estándares normativos de evaluación epistémica define, en cualquier situación o circunstancia, un "error de razonamiento" (Gigerenzer y Goldstein 1996, p. 4). Sin embargo, los simpatizantes de la tesis de racionalidad - a diferencia de los de la tesis de irracionalidad- los atribuyen a fallos en la ejecución (esto es, a distracciones motivacionales que no tienen que ver con nuestra capacidad para razonar). Analicemos la tesis de irracionalidad.

Tversky y Kahneman (1982) y Wason (1966), entre otros psicólogos, sostienen que la descripción más adecuada de la conducta raciocinativa observada apela a la utilización de reglas heurísticas que nos permiten resolver los problemas rápida y eficientemente, aunque no siempre de manera correcta. Si aceptamos esto, y si una descripción correcta de la conducta raciocinativa de los seres humanos nos permite caracterizar apropiadamente su competencia de razonamiento, entonces podemos aceptar que nuestra competencia racional está constituida por reglas heurísticas. De esto, sin embargo, no se sigue, como los simpatizantes de la tesis de irracionalidad sostienen, que los seres humanos seamos irracionales. Para sostener esta conclusión, los psicólogos arguyen que las reglas heurísticas que utilizamos se caracterizan por llevarnos, de manera sistemática, a razonar de forma diferente de cómo lo habríamos hecho si nos guiáramos por los principios del razonamiento y, por tanto, a utilizar principios diferentes de aquellos que supuestamente establecen cómo está epistémicamente permitido razonar. Esto, según ellos, indica que nuestra competencia es deficiente o defectuosa ya que no puede caracterizarse mediante los principios normativos del razonamiento o se caracteriza con principios diferentes de éstos. Si "ser racional" significase tener una competencia racional constituida por las supuestas normas de razonamiento, entonces sería posible concluir que los seres humanos somos irracionales. 
Uno de los experimentos llevados a cabo, "el de los ingenieros y los abogados", intenta mostrar que los seres humanos sistemáticamente utilizamos la llamada "heurística de representatividad" para juzgar probabilidades. Esta regla nos ayuda a estimar la probabilidad de que un suceso ocurra en términos de la semejanza que éste tiene con otro suceso del mismo tipo o, en otras palabras, en términos de hasta qué punto es representativo de una clase. Por ejemplo, si $A$ es altamente representativo de $B$, la probabilidad de que $A$ tenga su origen en $B$ se juzga muy alta y si, por otro lado, $A$ no es similar a $B$, la probabilidad de que $A$ tenga su origen en $B$ se juzga muy baja. (Tversky y Kahneman 1982, p. 4). El experimento consiste en lo siguiente: se pide a un grupo de sujetos que estimen la probabilidad de que Juan sea ingeniero con base en la siguiente información: Juan es miembro de un grupo de cien personas elegidas al azar, setenta de las cuales son ingenieros y treinta abogados. Además se provee la siguiente descripción de Juan: "es un hombre de treinta años. Esta casado y no tiene hijos. Tiene muchas habilidades y motivaciones, de manera que promete ser exitoso en su campo. Tiene buenas relaciones con sus colegas" (Tversky y Kahneman 1982).

Dada la información y la idea de los experimentadores de que los sujetos deben estimar la probabilidad de que ocurra un suceso con base en las probabilidades iniciales, su expectativa era que los sujetos encuestados juzgaran en 0.7 la probabilidad de que Juan fuese ingeniero. Esto es, desde su punto de vista, los juicios de probabilidad que emitieran los encuestados deberían basarse en la proporción de ingenieros del grupo de cien personas al que Juan pertenece. Sin embargo, la mayoría de los sujetos respondió que era de 0.5 y, en general, el juicio emitido apelaba a la semejanza de la descripción de Juan con algún estereotipo de los ingenieros (y de los abogados), en otras palabras, a qué tan representativa de los ingenieros era la descripción de Juan.

Según los defensores de la tesis de irracionalidad, experimentos como el descrito muestran una fuerte tendencia de los sujetos a asignar probabilidades a partir de la cercanía con este- 
reotipos, y sin tomar en cuenta información relevante a la que tienen acceso (por ejemplo, hacen caso omiso del hecho de que en el grupo de cien personas al que pertenece Juan hay setenta ingenieros y sólo treinta abogados). Esto sólo podría describirse como resultado de distracciones y otros factores psicológicos si los sesgos observados no fuesen estables, esto es, no se repitieran después de hacer ver a los sujetos que sus juicios son erróneos, por qué lo son y cuál sería un juicio correcto. Sin embargo, la aplicación del mismo experimento al mismo grupo de sujetos ha mostrado una clara tendencia de estos últimos a aferrarse a sus elecciones iniciales: es común, por ejemplo, que los sujetos cometan los mismos errores o intenten justificar la respuesta emitida aun después de haber recibido (y aceptado como satisfactoria) una explicación de por qué los principios generales detrás de sus respuestas son incorrectos.

A partir de evidencia como la anterior, los psicólogos cognoscitivos afirman que los seres humanos llevamos a cabo inferencias siguiendo una serie de atajos también llamados "reglas heurísticas" que se caracterizan por mostrar algunos sesgos en nuestro razonamiento, donde un sesgo es una fuente de error sistemático y predecible que, según los diseñadores de los experimentos, proviene de la imposibilidad de tomar en cuenta las características relevantes o una tendencia a responder a una característica irrelevante. ${ }^{6}$ Los errores cometidos, desde su perspectiva, deben atribuirse a la utilización de dichas reglas. Así, la descripción más adecuada de la conducta raciocinativa observada apela a la constitución de nuestra competencia racional: ésta se conforma por reglas heurísticas.

Uno de los razonamientos que, según los defensores de la tesis de irracionalidad, sustenta la inferencia de esta conclusión hacia la idea de que los seres humanos somos irracionales es que el uso sistemático de reglas heurísticas indica que el

${ }^{6}$ Evans (1984) afirma que un sesgo es "una fuente de error sistemático y no azaroso" (p. 462; la traducción es mía). Stanovich y West, por su parte, sostienen que "en la literatura sobre heurísticas y sesgos, el término sesgo se reserva para las desviaciones sistemáticas del razonamiento normativo y no hace referencia a errores transitorios de procesamiento" $(2000$, p. 646; la traducción es mía). 
razonamiento humano tiende a desviarse de la conducta epistémicamente permitida y, por tanto, los sesgos observados en la resolución de problemas del razonamiento deben interpretarse como errores que provienen de las limitaciones de la mente humana para interpretar la información accesible de manera tal que sus juicios no se desvíen sistemáticamente de las respuestas correctas. En este sentido, los psicólogos afirman que nuestras limitaciones cognoscitivas constituyen una imposibilidad para razonar, la mayor parte del tiempo, de acuerdo con las normas del razonamiento: las reglas heurísticas que usamos no son una formulación explícita de ninguna de las supuestas normas del razonamiento, de manera que las reglas que utilizamos en nuestro razonamiento cotidiano son diferentes de las reglas asociadas a los principios normativos del razonamiento.

Ahora bien, puesto que nuestra competencia puede caracterizarse apropiadamente con reglas heurísticas, y que utilizarlas en el razonamiento significa, según los psicólogos, hacerlo de acuerdo con principios diferentes de los subyacentes en las normas de razonamiento - esto es, razonar erróneamente-, nuestra competencia es deficiente o defectuosa: no contiene los principios de razonamiento. Si "ser racional" significa tener una competencia acorde con ciertos principios de razonamiento que no son heurísticos, la incompetencia observada para razonar sistemáticamente de acuerdo con aquellos principios no heurísticos del razonamiento nos autoriza a afirmar que los seres humanos somos irracionales. Este argumento puede reconstruirse como sigue:

1. O bien los sujetos razonan de acuerdo con los principios del razonamiento correcto y toda conducta que no se ajuste a ellos puede explicarse en términos de factores psicológicos ajenos a la competencia de razonamiento; o bien razonan de acuerdo con reglas bien definidas y claramente distinguibles, pero diferentes de los principios normativos del razonamiento correcto y los errores no pueden explicarse exclusivamente a través de factores psicológicos ajenos a la competencia. 
2. Los errores detectados en los experimentos no pueden explicarse como fallos en la ejecución, esto es, en términos de factores psicológicos ajenos a la competencia.

3. Si 1 y 2 , entonces los errores deben explicarse como fallos en nuestra competencia.

4. Si 3 es correcta y si aceptamos que una descripción correcta de nuestro razonamiento nos permite dar cuenta de la constitución de nuestra competencia racional, entonces podemos afirmar que nuestra competencia está constituida por principios del razonamiento diferentes de los principios de razonamiento correcto.

5. Dada la definición de "ser racional" expresada en la primera premisa formulada al inicio de esta sección, si 4 es correcta podemos concluir que los seres humanos somos irracionales.

Examinemos la crítica que los defensores de la tesis de racionalidad hacen de esta argumentación.

\section{La tesis de racionalidad}

Los defensores de la tesis de racionalidad sostienen que los errores observados en la resolución de problemas del razonamiento no denotan una divergencia entre nuestra habilidad para razonar y los principios del razonamiento; más bien muestran que a veces nos equivocamos: los seres humanos no siempre podemos utilizar los principios correctos como debiéramos. En otras palabras, los errores observados son resultado de la forma en que se aplican dichos principios en situaciones específicas o de factores que interfieren con el razonamiento humano. ${ }^{7}$

${ }^{7} \mathrm{El}$ argumento que se desprende de la tesis de racionalidad puede esquematizarse como sigue: 1) La interpretación correcta de la evidencia que arrojan los experimentos en psicología cognoscitiva es la que explica que los errores cometidos por los sujetos encuestados se deben a fallos en la ejecución; 2) si 1 es verdadera, entonces no es posible afirmar que los seres humanos razonamos (sistemáticamente) en desacuerdo con los principios de razonamiento; 3) si 
La idea de que los errores del razonamiento no necesariamente son reflejo del desacuerdo entre nuestra competencia y los principios normativos del razonamiento ha sido defendida de diversas maneras. En lo que sigue examinaré sólo el argumento que afirma que no puede haber una divergencia entre nuestra competencia racional y los principios normativos del razonamiento, ya que ambos provienen de un proceso de equilibrio reflexivo cuyos insumos son nuestras intuiciones acerca de lo que puede ser considerado como un buen razonamiento. ${ }^{8}$

Antes de examinar esta posición es importante recalcar que uno de los supuestos en que se apoya establece que cualquier instancia de una persona que no razona de acuerdo con los principios normativos del razonamiento debe interpretarse como un error de ejecución. En este sentido, los resultados experimentales nos permiten describir la conducta que a menudo nos lleva a cometer errores de ejecución, pero no nos dan los elementos suficientes para evaluarla como incorrecta. ${ }^{9}$

Goodman (1965) enuncia la prueba del equilibrio reflexivo en los siguientes términos:

tanto 2 como una descripción adecuada de nuestra conducta raciocinativa apuntan a la constitución de nuestra competencia racional, entonces no es posible afirmar que nuestra competencia de razonamiento está constituida por los principios incorrectos o por principios de razonamiento diferentes de los correctos; 4) dado que "ser racional" es tener una competencia constituida por los principios normativos del razonamiento, si 3 es correcta podemos concluir que los seres humanos somos racionales.

${ }^{8}$ Otro de los argumentos importantes en esta dirección sostiene que cualquier explicación plausible de la conducta raciocinativa de los seres humanos debe partir de un principio de caridad para la interpretación del comportamiento cognoscitivo de los sujetos. Desde esta perspectiva, la interpretación que los psicólogos hacen es incorrecta porque no es consistente con el supuesto de que cualquier persona a la que tratamos de entender es, en principio, racional, y que sostiene al principio en cuestión. En este artículo no ahondaré en esta argumentación, para un análisis más detallado de la misma, $c f r$. Eraña 2003.

${ }^{9}$ Cohen dice: "no se ha demostrado que la gente común y corriente posea programas incorrectos para el razonamiento deductivo o probabilístico, o que le hagan falta los programas correctos. Pero, de diversas maneras, la gente puede claramente cometer errores $[\ldots]$ o los principios que realmente guían sus juicios intuitivos particulares pueden ser interpretados erróneamente o apreciados inadecuadamente" (Cohen 1986, p. 186; la traducción es mía). 
Una regla se enmienda si da lugar a una inferencia que no estamos dispuestos a aceptar; una inferencia se rechaza si viola una regla que no estamos dispuestos a enmendar. El proceso de justificación es el delicado proceso de hacer ajustes mutuos entre las reglas y las inferencias aceptadas; y en el acuerdo alcanzado descansa la única justificación para cualquiera de ellas (Goodman 1965, p. 64; la traducción es mía). ${ }^{10}$

Cohen (1986) afirma que la estrategia del equilibrio reflexivo puede utilizarse tanto para dar cuenta de cómo las normas del razonamiento correcto están justificadas, como para dar cuenta de la constitución de nuestra competencia racional: el conjunto de reglas que obtenemos al coleccionar nuestras intuiciones acerca de inferencias particulares y hacerlas explícitas en una teoría idealizada sobre el razonamiento y el conjunto de reglas justificadas son idénticos. Esta idea puede formularse de la siguiente manera:

1. Los principios normativos del razonamiento provienen de un proceso de equilibrio reflexivo cuyo insumo son nuestras intuiciones acerca de lo que constituye un buen razonamiento.

2. Una teoría descriptiva de la competencia racional proviene de un proceso idéntico al anterior — esto es, de un proceso de equilibrio reflexivo cuyo insumo son nuestras intuiciones acerca de lo que constituye un buen razonamiento.

3 . Si 1 y 2 , entonces, puesto que ambas tienen el mismo origen, la competencia racional debe igualar a los principios normativos del razonamiento. (Stein 1996, p. 142)

Si este argumento es correcto, entonces una descripción adecuada de la competencia racional de los seres humanos no puede

10 " $A$ rule is amended if it yields an inference we are unwilling to accept; an inference is rejected if it violates a rule we are unwilling to amend. The process of justification is the delicate one of making mutual adjustments between rules and accepted inferences; and in the agreement achieved lies the only justification for either." 
afirmar que ésta diverge de los principios mencionados. Analicémoslo con más cuidado.

Desde el punto de vista de Cohen (1986), si bien es cierto que una descripción correcta de las maneras en que razonamos nos da pistas importantes de cómo está constituida nuestra competencia racional, para generarla no es suficiente explicar el comportamiento real de los sujetos en casos particulares; es necesario entender cuáles son las normas subyacentes en dicho razonamiento y, al mismo tiempo, cuáles son las intuiciones detrás de las normas. La idea central es que el fundamento del razonamiento son nuestras nociones intuitivas de aceptabilidad epistémica, pero no hay una única teoría que pueda modelarlas satisfactoriamente. Si bien las reglas de la lógica y del cálculo de probabilidades son el reflejo de algunas de nuestras nociones intuitivas de lo que es razonar correctamente, no parece plausible hablar de un único sistema normativo que pueda modelar lo que comúnmente llamamos "racionalidad", ni de una única teoría formal que pueda dictaminar cuáles son las respuestas correctas para ciertos problemas o tipos de problema específicos. Así, una descripción correcta de nuestra conducta racional requiere partir del supuesto de que somos racionales, aceptar que puede haber más de una respuesta razonable para cada problema y entender cuáles son las intuiciones que descansan en las respuestas de los sujetos para, a partir de ahí, extraer la norma del razonamiento que se ha utilizado.

Cohen considera que las aseveraciones apresuradas de los psicólogos respecto a la racionalidad humana se deben a una confusión importante entre cuestiones descriptivas y normativas o evaluativas. Por un lado, al afirmar que nuestra competencia es defectuosa, los psicólogos parecieran olvidar que los experimentos llevados a cabo fueron diseñados para diagnosticar el tipo de proceso que utilizan los sujetos en la resolución de problemas, esto es, para dar una descripción evaluativamente neutral de los procesos, no para evaluar la ejecución de los sujetos frente a ellos. Además, la observación de la conducta racional de algunos sujetos frente a ciertos problemas específicos debería generar una explicación psicológica interesante acerca de cómo pueden 
los sujetos haber entendido un problema, pero no da cuenta de la constitución de nuestra competencia de razonamiento. Veamos.

Los psicólogos explican las respuestas emitidas por los sujetos encuestados en términos de la violación de ciertos principios normativos del razonamiento debida al uso de ciertas heurísticas muy útiles, pero que a menudo nos conducen a errores sistemáticos. El caso de los "ingenieros y los abogados" no es el único que corrobora esta generalización; los resultados de muchos otros experimentos han sido explicados de la misma manera, aunque a partir de la identificación de distintos sesgos: mientras que el experimento de los "ingenieros y los abogados" les permitió identificar la llamada "falacia de las tazas porcentuales", el de "Linda" los llevó a encontrar la llamada "falacia de la conjunción". Veamos en qué consiste este último y la falacia que involucra.

A un grupo de sujetos se les leyó la siguiente descripción de Linda: "tiene 31 años, es soltera, desenvuelta y muy brillante. Hizo su licenciatura en filosofía. Cuando era estudiante estuvo muy preocupada por la discriminación y la justicia social, también participó en manifestaciones antinucleares." Después se les pidió que juzgaran cuál de las siguientes alternativas era más probable: B) Linda trabaja en un banco; F) Linda trabaja en un banco y está involucrada en el movimiento feminista. El $85 \%$ de los participantes eligió $\mathrm{F}$, lo cual, según Tversky y Kahneman (1983, p. 299), constituye un error o una falacia: la probabilidad de la conjunción de dos eventos nunca puede ser mayor que la de uno de sus constituyentes. De acuerdo con las respuestas recibidas, los autores explicaron que para responder los sujetos encuestados utilizaron la heurística de la representatividad que, además de la "falacia de las tazas porcentuales", lleva consigo la "falacia de la conjunción".

Estas explicaciones presuponen una teoría formal específica como la norma incontrovertible; en el caso de los "ingenieros y los abogados", por ejemplo, se presupone la teoría bayesiana como la norma. Desde la perspectiva de los psicólogos, el razonamiento de los sujetos debe compararse y evaluarse conforme 
a lo que establece dicha norma. Si esto fuese correcto, entonces cada problema del razonamiento (o cada tipo de problema) aceptaría una (y sólo una) respuesta correcta: aquella que está acorde con la norma incontrovertible pertinente y, por tanto, cualquier respuesta diferente de la sancionada por la norma en cuestión sería indicativa del uso de un procedimiento defectuoso que no obedece a ninguno de los principios normativos del razonamiento o que, en todo caso, está vinculado a un principio diferente de los que subyacen en las normas del razonamiento. ${ }^{11}$ Si el supuesto mencionado fuese correcto, entonces las reglas heurísticas que explican muchas de las respuestas de los sujetos deberían ser vistas como procedimientos defectuosos. ${ }^{12}$

Sin embargo, esta explicación y el supuesto que en ella subyace son cuestionables. Cohen argumenta que las respuestas emitidas pueden considerarse como correctas por un sistema normativo $N$ sustentado en una concepción particular de la probabilidad, y como incorrectas desde la perspectiva de un sistema normativo $N 1$. Tanto la respuesta sustentada por $N$ como la sancionada por $N 1$ son razonables si la presentación del problema así lo indica. Gigerenzer (2000, p. 247), en coincidencia con Cohen, afirma que, de acuerdo con múltiples interpretaciones de la probabilidad, los resultados obtenidos por los psicólogos en los experimentos no son errores o desviaciones de los principios subyacentes en la teoría de la probabilidad. ${ }^{13}$

${ }^{11}$ El supuesto que está detrás de esta idea es que es posible establecer un vínculo unívoco entre los mecanismos de razonamiento que los sujetos deben utilizar para resolver correctamente los problemas planteados en los experimentos y aquellos que está epistémicamente permitido utilizar.

${ }^{12} \mathrm{Si}$ a esto le añadimos el supuesto de que las reglas con las que comúnmente razonamos caracterizan apropiadamente nuestra habilidad para razonar, entonces podríamos aceptar que los seres humanos tenemos una competencia racional deficiente o defectuosa, esto es, una competencia constituida por algunos principios del razonamiento incorrectos o diferentes de los correctos.

${ }^{13}$ Gigerenzer dice: "¿Se quebranta la teoría de la probabilidad si nuestro grado de creencia (confianza) en un suceso único (por ejemplo, que una respuesta particular sea correcta) es diferente de la frecuencia relativa de las respuestas correctas que generamos a largo plazo? La respuesta es 'no'. De hecho no es una violación de acuerdo con múltiples interpretaciones de la probabilidad" (Gigerenzer 2000, p. 246; la traducción es mía). 
La interpretación frecuentista de la probabilidad, por ejemplo, sostiene que la teoría de la probabilidad es acerca de frecuencias y $n o$ de sucesos singulares. Desde esta perspectiva, elegir $\mathrm{F}$ en el experimento de Linda no quebranta la teoría de la probabilidad, ya que el problema del razonamiento planteado no tiene nada que ver con la teoría de la probabilidad: a los participantes se les pidió que juzgaran la probabilidad de un suceso singular (la probabilidad de que Linda trabaje en un banco) y no de ciertas frecuencias. Dice Gigerenzer:

Para sintetizar la cuestión normativa, lo que se llama "falacia de conjunción" parece una violación de algunas teorías subjetivas de la probabilidad, incluida la teoría bayesiana. Sin embargo, no quebranto una perspectiva importante de la probabilidad, la concepción frecuentista. (Gigerenzer 2000, p. 250; la traducción es mía.)

Las reglas probabilistas frente a las cuales los psicólogos han evaluado las respuestas de sus participantes son una pequeña muestra de aquellas reglas que caracterizan la teoría de la probabilidad. Así, hay pocas razones para pensar que las conclusiones que los experimentadores han extraído sustentan la idea de que los seres humanos somos irracionales. No sólo no han mostrado que la estadística bayesiana pueda considerarse como la norma pertinente para evaluar nuestro razonamiento probabilista, sino que tampoco nos han dado buenas razones para afirmar que cada tipo de problema tiene una única respuesta correcta. Así, aun concediendo que las normas del razonamiento correcto refieren a las del cálculo de probabilidades (y a las del cálculo proposicional), no habría razón para afirmar que la evidencia obtenida en los experimentos llevados a cabo nos permita aseverar que los seres humanos no razonamos, la mayor parte del tiempo, de acuerdo con las reglas de la lógica o del cálculo de probabilidades.

Ahora bien, el argumento aquí examinado a favor de la tesis de racionalidad, al igual que la tesis de irracionalidad, se sostiene en la idea de que la evaluación del comportamiento racional 
involucra reglas independientes de contenido, esto es, reglas cuyos principios subyacentes no están referidos a las características específicas del contenido del material que es objeto del razonamiento. ${ }^{14}$ Sin embargo, a diferencia de la de irracionalidad, el argumento en cuestión parte de la idea de que la presentación del problema influye significativamente en la respuesta (o el tipo de respuesta) que elegirá el sujeto que lo enfrenta y, por tanto, ésta no debe evaluarse según el supuesto de que la norma del razonamiento correcto es aquella (y sólo aquélla) que se expresa en términos de las teorías presupuestas por los psicólogos.

Como ya lo mencioné, uno de los supuestos compartidos por las tesis de racionalidad e irracionalidad es que hay un único conjunto de normas del razonamiento cuya corrección proviene de un análisis detallado de nuestros conceptos de aceptabilidad epistémica. Así, la corrección de las reglas que utilizamos en nuestro razonamiento cotidiano es independiente de la información disponible, de la manera como ésta se presenta y de cualquier otro factor que no esté directamente vinculado con los estándares de evaluación provenientes del análisis antes mencionado. Según Cohen, esto no implica que sea posible hablar de una única respuesta correcta para cada problema o tipo de problema y, por tanto, la idea de los psicólogos de que es posible utilizar un único sistema normativo para explicar y justificar el

\footnotetext{
${ }^{14}$ La noción de "independencia de contenido" es ambigua y controversial. Esto se debe, en parte, a que no hay una caracterización clara de lo que es un contenido. Así, en cierto sentido es posible afirmar que la lógica tradicional es "libre (o independiente) de contenido" ya que las reglas que la conforman se aplican a varias expresiones del mismo tipo si abstraemos su forma común. En otro sentido, sin embargo, aquélla es dependiente de contenido: lo que hace es privilegiar y formalizar ciertos contenidos lógicos. Esta última posición es claramente defendida por Tarski: "hay términos que ocurren en la mayoría de las proposiciones de la aritmética de carácter mucho más general, términos que se encuentran constantemente tanto en consideraciones de la vida cotidiana como en cualquier campo posible de la ciencia, y que representan un medio indispensable para transmitir el pensamiento humano y para llevar a cabo inferencias en cualquier campo; palabras como 'no', 'y', 'o', 'es', 'todo', 'algunos', y muchos otros que entran aquí” (Tarski 1965, p. 18; la traducción es mía).
} 
razonamiento real de los seres humanos en circunstancias específicas es incorrecta. Cohen afirma que para hablar de una única respuesta correcta sería necesario un consenso previo entre el experimentador y el sujeto encuestado, en el cual se dieran a conocer las premisas que se utilizan en el planteamiento y el dominio que se busca estudiar (Cohen 1986, p. 187). Así, para este autor, la conclusión de la tesis de irracionalidad es incorrecta porque su interpretación de los resultados experimentales desdeña la importancia de la presentación del problema y porque la descripción que da de nuestra conducta raciocinativa no es adecuada. Para apoyar estas ideas, pueden usarse los resultados de la tarea de selección concreta.

En 1966, Wason hizo famosos los resultados de la llamada "tarea de selección" que consiste en lo siguiente: a un grupo de sujetos se le presentan cuatro cartas (cubiertas por un lado y descubiertas por el otro) que muestran una vocal, una consonante, un número par y un número non; respectivamente "A", "K", "4" y "7" y se le pregunta cuáles cartas es necesario voltear para saber si se cumple la regla "si la carta tiene una vocal de un lado, entonces tiene un número par del otro". En esta versión del experimento, la mayoría de los sujetos respondió "A" o "A y 4", lo cual contradice la regla según la cual para poner a prueba un condicional deben examinarse los casos en que el antecedente es verdadero para asegurase que el consecuente es también verdadero, y los casos donde el consecuente es falso para asegurarse de que el antecedente es falso. Los sujetos deberían haber respondido “A y 7" (Wason y Johnson-Laird 1972).

Las expectativas de los experimentadores en torno al razonamiento deductivo de los seres humanos fueron mucho mejor satisfechas en los resultados arrojados por una versión concreta de la misma tarea. La diferencia entre estas versiones ha sido expresada en términos del contenido del material que cada una de ellas presenta: abstracto o concreto. Así, en la versión concreta, las cartas que se presentan a los sujetos exhiben objetos o situaciones que refieren a cuestiones de su vida cotidiana; por ejemplo, en vez de letras y números, las cartas podrían mostrar nombres de ciudades y modos de transporte, y el condicional 
que los sujetos deben poner a prueba podría afirmar "si voy a la ciudad de México viajo en autobús".

Según Cohen, si bien cometemos errores al enfrentarnos con problemas abstractos, el hecho de que razonemos correctamente en versiones concretas del mismo tipo de problema muestra la importancia que adquiere la presentación del problema para nuestro razonamiento: ésta influye significativamente en la representación que nos hacemos de la información relevante para llevar a cabo las inferencias requeridas y correctas. La cuestión es que la manera como se presenta la información en los diferentes problemas apunta a una forma particular de entender las ocurrencias de partículas lógicas en las oraciones del lenguaje natural, o a una concepción específica de la probabilidad, lo cual lleva a los sujetos a elegir la solución acorde con dicha concepción.

Cohen ilustra esta idea con algunos ejemplos. En relación con las partículas lógicas examina, entre otros, los resultados de un experimento llevado a cabo por Rips (1984) en el que un número importante de sujetos tendían a negar la validez del argumento que involucraba la inferencia de una premisa con la forma ' $p$ ' a una conclusión con la forma ' $p$ o $q$ '. De acuerdo con Cohen, si no suponemos que los seres humanos comunes y corrientes siempre usamos y entendemos las conectivas elementales del lenguaje natural de forma veritativo-funcional (esto es, de modo que la proposición de la forma ' $p$ o $q$ ' sea verdadera si y sólo si $p$ y $q$ no son ambas falsas), entonces podemos interpretar los resultados de Rips como si mostraran diferencias individuales en la manera en que los distintos sujetos entienden y utilizan dichas conectivas (Cohen 1986, p. 151). Con respecto al razonamiento probabilista, el autor en cuestión sostiene que es difícil saber si un sujeto concibe la probabilidad como frecuencias relativas o como probabilidades subjetivas, por ejemplo. Así, la manera en que se formule el problema de razonamiento y la concepción intuitiva de un sujeto $S$ desempeñarán un papel importante en la respuesta que $S$ emita: si la información se presenta de una forma y la pregunta que debe responder $S$ se formula en términos de sucesos singulares, pero $S$ concibe a la 
probabilidad como frecuencias relativas, entonces probablemente emita una respuesta incorrecta desde el punto de vista del teorema de Bayes, de acuerdo con el cual la probabilidad inicial de un suceso singular es información relevante para el razonamiento que se llevará a cabo. Cohen dice con respecto al primer ejemplo examinado:

El papel que una persona le otorga a una partícula lógica específica, como "o", "si", etc., en su interpretación o entendimiento de sus propias aseveraciones y de las de otros sujetos es indistinguible de los patrones de contradicción lógica, verdad necesaria e inferencia lógicamente válida a los que supone que el uso de dichas partículas da lugar. Así, para poder dar cuenta de lo que quiere decir, normalmente tenemos que dar por hecho que no está cometiendo ningún error lógico [...] Pero lo que resulta imposible, con respecto a la deducibilidad lógica, es alcanzar una determinación firme de cómo una persona entiende las ocurrencias de las partículas lógicas lo que es bastante independiente de determinar cuáles son sus intuiciones particulares acerca de la contradicción lógica y la deducibilidad. (Cohen 1986, p. 154; la traducción es mía) ${ }^{15}$

Así, desde su punto de vista, aunque no todas las respuestas emitidas por los sujetos satisfagan las expectativas de los experimentadores, no es posible afirmar que nuestras intuiciones acerca de la contradicción lógica o de la deducibilidad sean incorrectas.

En resumen, los defensores de este argumento a favor de la racionalidad humana consideran que las diferentes teorías

15 "the role which a person assigns to a particular logical particle, such as 'or', 'if', etc., in his interpretation or understanding of his own and other people's utterances is indistinguishable from the patterns of logical contradiction, necessary truth, and logically valid inference to which he supposes that the use of these particles gives rise. So, in order to find out what he means, you normally have to assume that he is not committing any logical errors [...] But what is impossible, in regard to logical deducibility, is to achieve some firm determination of how a person understands occurrences of logical particles that is quite independent of determining what his singular intuitions are about logical contradiction and deducibility." 
específicas en que se hacen explícitos los principios del razonamiento nos permiten caracterizar nuestra competencia racional, pero los resultados experimentales no nos dan los elementos suficientes para aseverar que esta competencia está constituida por principios de razonamiento diferentes de los correctos: lo único que muestran es que la concepción de probabilidad en que se construyen los juicios o la manera de entender las partículas lógicas depende, en gran medida, de cómo se formulan las instrucciones y, por tanto, la solución que el sujeto elija por considerarla adecuada dependerá de cómo entienda él el problema. Cohen dice:

podemos empezar a ver cómo la concepción de probabilidad en términos de la cual un sujeto interpreta su tarea le es señalada uniformemente en cada caso por el fraseo y el contenido de sus instrucciones y la situación en que dichas instrucciones le son dadas (frente al bagaje de su propia experiencia y educación y cualquier otra diferencia individual que sea relevante para su ejecución cognoscitiva. (Cohen 1986, p. 58; la traducción es mía)

Una caracterización adecuada de nuestra competencia racional requiere partir del supuesto de que todos los sujetos razonan, en general, correctamente y sus errores se explican como resultado de distracciones motivacionales o psicológicas. Si esto fuese correcto, entonces podríamos afirmar que la conducta racional de los sujetos se ajusta, la mayor parte del tiempo, a las reglas del razonamiento, y los errores que cometen pueden ser atribuidos a fallos significativos en su ejecución, pero no a inconsistencias sistemáticas en su competencia (García 1999).

\section{Reglas heurísticas, razonamiento y racionalidad}

En esta sección argüiré que una noción alternativa de norma del razonamiento no sólo nos permite dar una explicación plausible de los errores cometidos por los sujetos en los experimentos de psicología cognoscitiva aquí examinados, sino que también nos da elementos para proponer una noción de "racionalidad" que sea más acorde con las capacidades y limitaciones reales de 
los seres humanos. Sostendré, en coincidencia con Martínez y Gigerenzer, ${ }^{16}$ que el contenido del material de los problemas del razonamiento, la manera como se presenta la información y el contexto cognoscitivo del sujeto que lleva a cabo un razonamiento deben tomarse en cuenta para dar una descripción correcta de su conducta raciocinativa y, por tanto, para dar cuenta de cómo está constituida su competencia racional.

Este planteamiento me llevará a defender la idea de que razonar correctamente implica hacerlo de acuerdo con reglas del razonamiento que están diseñadas para resolver una clase limitada de problemas en el marco de un dominio específico. El punto de partida de mi argumentación será la idea de que los defensores de la tesis de irracionalidad están en lo correcto al afirmar que la descripción más adecuada de la conducta raciocinativa observada en los experimentos es aquella que apela al uso de reglas heurísticas. Sin embargo, a diferencia de lo que sostiene dicha tesis, afirmaré que ello no sólo no implica que los seres humanos seamos irracionales, sino que nos da una pauta para entender de qué manera somos racionales. Si bien es cierto que razonar correctamente implica el uso de los principios que refieren a aquellos que subyacen en las reglas de la lógica y del cálculo de probabilidades, también implica el uso de reglas heurísticas, y éstas son reglas "cuyo dominio de aplicación está restringido a cierto ámbito más o menos específico de la actividad humana en el que operan sujetos con determinadas características doxásticas..." (García 1999, p. 2), que tal vez no sean formulables en términos de principios generales y que muestra un sesgo que las caracteriza, esto es, que en un número importante de situaciones conducen a errores sistemáticos. ${ }^{17}$

\footnotetext{
${ }^{16}$ Es importante mencionar que los planteamientos de estos autores difieren en ideas cruciales, por ejemplo, mientras que para Gigerenzer (1991b, 1992) la racionalidad humana es, básicamente, una racionalidad instrumental que puede evaluarse en términos de los medios utilizados para alcanzar los fines buscados; para Martínez (2003) la racionalidad es una noción que debe articularse en términos de estándares de dependencia epistémica.

${ }^{17}$ Martínez dice: "Una propiedad muy importante de las reglas heurísti-
} 
Para defender estas ideas examinaré nuevamente el argumento sostenido por los psicólogos y analizaré algunas de las estrategias que pueden seguirse para bloquear la inferencia hacia la conclusión de irracionalidad. Una reconstrucción del argumento en cuestión es la siguiente:

1. Si los seres humanos somos racionales, entonces razonamos de acuerdo con los principios normativos del razonamiento.

2. Los principios normativos del razonamiento refieren a aquellos (y sólo a aquellos) que provienen de las reglas de la lógica proposicional y del cálculo de probabilidades, entre otros sistemas de reglas.

3. La evidencia obtenida en los experimentos llevados a cabo nos permite aseverar que los seres humanos no razonamos, la mayor parte del tiempo, de acuerdo con las reglas de la lógica o del cálculo de probabilidades.

4. Si 2 y 3, entonces tenemos buenas razones para afirmar que los seres humanos razonamos, la mayor parte del tiempo, de acuerdo con principios del razonamiento diferentes de los principios normativos del razonamiento.

5. Si 1 y 4, entonces, los seres humanos no somos racionales.

La inferencia que trazan los psicólogos hacia 4, y que les permite sostener la conclusión enunciada en 5 , se apoya en la idea de que las desviaciones documentadas de nuestro razonamiento respecto al (supuestamente) correcto dan cuenta de las reglas que constituyen nuestra competencia racional. Puesto que dichas reglas son diferentes de las reglas normativas del razonamiento y que la evidencia obtenida en los experimentos muestra que los seres humanos, la mayor parte del tiempo, razonamos de acuerdo con ellas, es posible afirmar que los seres humanos razonamos, la mayor parte del tiempo, de acuerdo con reglas cas... [es que] el error generado por ellas tiene sesgos sistemáticos" (Martínez 2003, p. 96). 
diferentes de aquellas que provienen de los principios normativos del razonamiento. Así - y si las condiciones necesarias y suficientes para la racionalidad están dadas por la aplicación de los principios normativos del razonamiento-, podríamos concluir que los seres humanos somos irracionales. Es importante recordar que dos de los supuestos en que descansa la argumentación de los psicólogos son: a) hay una norma incontrovertible con la que deben confrontarse nuestros razonamientos cotidianos (y con la cual deben evaluarse dichos razonamientos), y b) las reglas del razonamiento correcto son reglas independientes de contenido, esto es, son reglas cuya formulación debe hacer referencia únicamente a la estructura lógica del conjunto de enunciados a los que la regla se aplica apropiadamente y, en este sentido, deben hacer abstracción del contenido de tales enunciados (García 1999, p. 3). ${ }^{18}$

El segundo de estos supuestos conduce hacia un universalismo respecto a las normas de razonamiento y un reduccionismo de la racionalidad. El primero de éstos establece que las normas del razonamiento deben ser aplicables a todas las expresiones del mismo tipo si abstraemos su forma común: ${ }^{19}$ las reglas en que dichas normas se manifiestan se deben enunciar formalmente, esto es, deben formularse en abstracción del contenido

${ }^{18} \mathrm{La}$ formulación planteada por García de una regla formal de razonamiento es esclarecedora. Afirma que una regla de esta naturaleza establece lo siguiente: "si $S$ tiene ciertas creencias cuyos contenidos tienen determinadas formas lógicas $F_{1}, \ldots, F_{n}$ (y si estas creencias son epistémicamente aceptables), entonces está epistémicamente permitido a $S$ inferir otra creencia con forma lógica $F_{m} "$ (García 1999, p. 4).

${ }^{19}$ Ésta es una formulación del llamado "formalismo" en lógica, según el cual una regla de lógica formal debe ser universal en su aplicación, independiente del contexto y libre del contenido. Es posible afirmar, sin embargo, que no toda concepción de la lógica formal coincide con lo mencionado anteriormente. Por ejemplo, una visión más reciente afirma que "en cierto sentido" las reglas que nos llevan a hacer inferencias correctas son dependientes de ciertos contenidos, como aquellos que se desprenden de las expresiones "y", "si, entonces", etc. Sin embargo, ninguna de estas versiones podría aceptar que la validez de las reglas mismas depende del contenido específico de una premisa y de una conclusión particulares. Ésta es la idea que me interesará sostener más adelante y a la que me referiré al hablar de normas dependientes de contenido. 
de los enunciados a los que se aplican y del contexto en que se aplican. Así, desde esta perspectiva, cualquier inferencia que llevemos a cabo (si es racional) debe hacer abstracción de la verdad o falsedad de las premisas involucradas en el razonamiento y llegar a la conclusión a través de la aplicación de la norma pertinente dada la forma de la expresión que sirve como información original. El reduccionismo, por su parte, establece que las condiciones necesarias y suficientes para considerar racional a un sujeto $S$ son independientes de las capacidades y limitaciones cognoscitivas de $S$, del medio ambiente en que $S$ esté inmerso y de las interacciones sociales que $S$ pueda tener con otros sujetos. El punto es que el funcionamiento de todo proceso de inferencia se conforma con una serie de principios normativos; puesto que dichos principios refieren a las reglas provenientes de sistemas formales (como la lógica o el cálculo de probabilidades), éstas deben poder modelar y explicar el razonamiento humano.

La idea de fondo en este planteamiento es que la estructura de la cognición debe detectarse en el nivel de los individuos: toda explicación de nuestro proceder racional debe hacer referencia exclusivamente a procesos de razonamiento que están "dentro de la cabeza" de cada sujeto. Martínez, en un tono crítico, afirma que el reduccionismo de la racionalidad entiende la cognición como

una "arquitectura de símbolos" que se busca estudiar haciendo abstracción del ambiente y de la cultura en la cual tiene lugar. [... Se parte de un agente cognitivo "simplificado" al que posteriormente se intenta agregar elementos culturales e históricos. Se asume, pues, de entrada, que el tipo de aspectos cualitativos de la experiencia que es posible modelar por medio de estructuras heurísticas no son algo real, sino algo "agregado" por el sujeto [... ]. (Martínez 2003, pp. 111-112)

Más adelante argüiré que si el supuesto b) es rechazado, entonces podemos abandonar la idea de que las normas del razonamiento necesariamente tienen un carácter formal y, más allá 
de esto, tendríamos buenas razones para poner en tela de juicio la identificación que comúnmente se hace entre normatividad y universalidad. Recordemos brevemente el argumento examinado en la sección anterior.

Para negar la conclusión de irracionalidad, los defensores de la tesis de racionalidad parten de la negación de la tercera premisa del argumento antes formulado y, con ello, rechazan la inferencia hacia 5. Cohen afirma que la posibilidad de "extraer la norma" que subyace en el razonamiento de los sujetos depende de conocer sus intuiciones respecto a lo que constituye un buen razonamiento, y esto requiere un proceso complejo en que algunas reglas son abandonadas si, después de considerarlo, no estamos dispuestos a aceptar la inferencia que ellas autorizan, o en el que algunas inferencias son rechazadas si ellas violan alguna regla que no estamos dispuestos a corregir. En otras palabras, para dar cuenta de las reglas que conforman nuestra competencia racional no es suficiente analizar el tipo de regla que los sujetos utilizan en situaciones específicas; también es necesario reunir nuestras intuiciones de lo que es razonar correctamente y capturarlas en una teoría idealizada que no sólo defina nuestro concepto de racionalidad, sino que también nos sirva de guía en nuestro razonamiento cotidiano. Si bien las reglas heurísticas utilizadas por los sujetos en los experimentos nos permiten describir ciertas condiciones psicológicas de los seres humanos, no nos permiten dar cuenta de la manera como está constituida nuestra competencia racional. La noción de racionalidad es normativa y, como tal, debe formularse en términos de los principios normativos que deben regir nuestra conducta racional; las reglas heurísticas no pueden formularse correctamente por medio de un enunciado de permisividad epistémica (García 1999, p. 3) y, por tanto, no sólo no pueden conformar nuestra noción intuitiva de racionalidad, sino que tampoco pueden referir a ningún concepto normativo. Así, una descripción correcta de nuestra competencia racional debe apelar a la noción de racionalidad (y viceversa), y los experimentos llevados a cabo pueden darnos una explicación psicológicamente interesante respecto a nuestra conducta raciocinativa, pero no 
pueden dar cuenta cómo está constituida nuestra habilidad para razonar.

Este argumento nos permite, en efecto, bloquear la inferencia a la irracionalidad: nuestra noción intuitiva de racionalidad puede manifestarse en distintas teorías (o interpretaciones de las mismas) de la inferencia lógica o probabilística, de modo que la explicación más plausible de los errores cometidos por los sujetos es aquella que parte del supuesto de que las reglas que conforman nuestra competencia racional son idénticas a aquellas que constituyen nuestra noción intuitiva de racionalidad $y$, por tanto, la evidencia obtenida por los experimentos no es suficiente para afirmar que los seres humanos somos irracionales. Sin embargo, nos obliga a rechazar la idea de que nuestra manera de ser racionales puede caracterizarse en términos de la estructura heurística de nuestro razonamiento.

Estoy de acuerdo en que existe cierto grado de convergencia entre las reglas que constituyen nuestra competencia racional y aquellas que conforman la noción de racionalidad aplicable a los seres humanos. En este sentido, coincido en que no es posible caracterizar la estructura de nuestro razonamiento a partir de un estudio de las circunstancias específicas en las que el resultado de la aplicación de una regla se desvía de la supuesta norma incontrovertible. Sin embargo, estoy en desacuerdo con la idea de que las reglas heurísticas que comúnmente utilizamos se refieren a procesos cognoscitivos interferidos por cuestiones psicológicas y que, por tanto, no pueden prescribir procesos cognoscitivos.

A diferencia de Cohen, quien afirma que la conclusión que debemos extraer de los experimentos mencionados es que hay factores psicológicos que distraen nuestra competencia y nos llevan a razonar erróneamente, Gigerenzer afirma que la conclusión adecuada es que las habilidades de los seres humanos para procesar la información son limitadas y que por ello tendemos a construir modelos simplificados del mundo que nos permiten tomar decisiones de manera expedita. Estas limitaciones se manifiestan en el uso de reglas heurísticas, las cuales, según Gigerenzer, deben entenderse como herramientas que nos permiten economizar la búsqueda de respuestas o soluciones en un 
ambiente complejo donde las alternativas para la acción no están dadas, sino que deben ser buscadas. Desde su punto de vista, la idea simplista de los psicólogos de que razonar correctamente significa aplicar una fórmula (o un algoritmo) - por ejemplo, la regla de Bayes - es muy cuestionable: la búsqueda economizada de respuestas es más eficiente que aplicar una fórmula y, en este sentido, las reglas heurísticas que utilizamos no sólo no refieren a procesos defectuosos, sino que apuntan a la manera en que los seres humanos intentamos resolver racionalmente los problemas. Para Gigerenzer (2000, 1992, 1991a), razonar correctamente es mucho más que aplicar una fórmula o utilizar mecánicamente una regla. Él ilustra esta idea con el análisis de un experimento mental que formula dos problemas del razonamiento con la misma estructura, pero cuyos contenidos son diferentes. Veamos.

A) Deseas comprar un coche nuevo. Hoy debes escoger entre dos alternativas: un $\mathrm{VW}$ o un Sentra. El único criterio que utilizas para dicha elección es la expectativa de vida para cada coche. Por una revista especializada tienes información de que, en una muestra de varios cientos de coches, el VW ha tenido mejores resultados con respecto al criterio que utilizarás para tomar la decisión. Justo ayer tu vecino te dijo que su VW nuevo se descompuso, ¿qué coche decides comprar?

B) Vives en la selva. Hoy debes escoger entre dos alternativas: dejar a tus hijos nadar en el río, o dejarlos trepar a los árboles. El único criterio que utilizas para la elección es la expectativa de vida de tus hijos. Tienes información de que en los últimos cien años sólo ha habido un accidente en el río, en el que un cocodrilo se comió a un niño, mientras que docenas de niños se han muerto al caer de los árboles. Justo ayer tu vecino te dijo que un cocodrilo se comió a su hijo, ¿a dónde dejas que vayan tus hijos?

Si aceptásemos que un "buen" razonamiento probabilista consiste en aplicar el mismo algoritmo una y otra vez a todo 
problema con la misma estructura, entonces los testimonios de los vecinos no deberían alterar la decisión ni del sujeto involucrado en A, ni del sujeto que está en la situación B. En ambas situaciones, las tazas porcentuales relevantes para tomar su decisión se actualizarían en un caso. Dicha actualización no debería generar una diferencia significativa para las expectativas que conforman el criterio de elección, de modo que las respuestas en ambos casos deberían ser las mismas: para A, comprar el $\mathrm{VW}$; para $\mathrm{B}$, dejar que su hijo vaya al río. Sin embargo, un padre puede usar la información provista por el testimonio para rechazar el algoritmo actualizado: en vez de insertar la nueva información en el algoritmo, quizá sospeche que el mundo del pequeño río ha cambiado y que ahora ahí viven muchos cocodrilos. Esto lo llevará a tomar la decisión "poco racional", desde el primer punto de vista, de dejar a sus hijos trepar los árboles.

Esta decisión no sería en absoluto "irracional", ni tampoco "poco racional" si la explicáramos según el supuesto de que la manera como se presenta la información, el contenido específico del problema del razonamiento en cuestión y el contexto en el que hay que tomar una decisión son fundamentales para describir nuestra conducta raciocinativa y, en última instancia, para evaluar nuestros procesos racionales. El problema de si la decisión del padre en $\mathrm{B}$ es racional no se reduce al problema de aplicar un algoritmo o de evaluar su decisión en función de la aplicación de una fórmula. Este problema involucra también cierto conocimiento implícito acerca de la estructura de un ambiente y, por tanto, antes de tomar una decisión debemos determinar si el mundo es suficientemente estable para utilizar estadísticas como base de nuestras decisiones.

Los experimentos mentales de Gigerenzer buscan mostrar que la posibilidad de mejorar nuestro razonamiento depende, en parte, de confiar en la estructura del ambiente, donde esta incluye, entre otras cosas, el espacio y el tiempo, o la perspectiva. En otras palabras, la posibilidad de entender por qué razonamos como lo hacemos, por qué nuestras elecciones son correctas y por qué nos es permitido razonar o actuar como está prescrito, requiere tomar en cuenta el contexto cognoscitivo de los sujetos 
en cuestión y, como parte de este contexto, es necesario poner atención a la manera como se presenta la información.

Estas ideas sugieren que el dominio de aplicación de las reglas del razonamiento no puede aislarse de las circunstancias en que se aplican, ni del contexto en que se plantean los problemas; en otras palabras, aquéllas sólo pueden individuarse en función de las características específicas de los problemas. Si esto es correcto, entonces no queda claro en qué sentido las reglas del razonamiento correcto podrían formularse abstrayéndolas de las circunstancias en que se lleva a cabo un razonamiento o de la manera como se presenta la información y, por tanto, tampoco estaría claro en qué sentido la estructura de nuestro razonamiento puede reducirse a la suma de unas cuantas reglas nítidamente distinguibles.

Así, la idea de fondo es que la manera en que se presenta la información para la aplicación de una u otra regla no sólo es importante; sino que es parte del problema de cómo y cuándo algo puede convertirse en una razón para otra cosa. Que cierta información pueda convertirse en evidencia suficiente para sostener alguna afirmación, para llevar a cabo una acción, para emitir un juicio o para realizar una inferencia depende, en gran medida, de la manera como se presenta esa información y del contexto en que esté inmerso el sujeto que llevará a cabo el razonamiento. Martínez (2003) dice que la presentación de la información es parte del contexto en que se utiliza correctamente una regla y, en este sentido, la corrección misma de algunas de las reglas del razonamiento depende, parcialmente, del tipo de circunstancia en que ellas se utilizan. Las normas del razonamiento correcto y las reglas en que aquéllas pueden manifestarse se establecen en un ámbito práctico que determina contextualmente aquello que es relevante en ciertas circunstancias, y la validez de la norma forma parte de un proceso cultural que tiende a coleccionar soluciones correctas a problemas frecuentemente encontrados. Veamos un ejemplo que nos permita ilustrar y aclarar esta idea.

A principios de 2001, la Secretaría de Desarrollo Social (SEDESO) encargó a un conjunto de académicos de su elección, a quienes llamó el "Comité Técnico para la Medición de la 
Pobreza" (en adelante CT), un estudio respecto a los niveles y proporciones de pobreza en México. La conclusión del CT fue que en el país hay tres estratos de pobreza y que el $65 \%$ de la población es pobre. Este dictamen, sin embargo, era insostenible desde el punto de vista del gobierno mexicano. Así, la SEDESo decidió cambiar el estándar de medición de pobreza: eliminó el estrato superior propuesto por el CT e introdujo un estrato intermedio entre los dos restantes. Con ello, la proporción de pobres disminuyó al 54\% y el estándar técnico del CT se convirtió en el estándar político del gobierno. La definición de pobreza en el país está ahora dada por la línea de pobreza más alta (52.17 pesos al día por persona en el medio urbano), ya que ésta establece, según el gobierno mexicano, el nivel de ingresos necesarios para satisfacer todos los bienes y servicios indispensables. Sin embargo, de acuerdo con el estándar de pobreza del CT, el nivel superior de SEDESO deja fuera servicios tan básicos como higiene personal y del hogar, electricidad y gas, comunicaciones, etc. (Boltvinik 2002).

Con este ejemplo se pretende mostrar, por un lado, cómo la presentación de la información es muy importante para que ella se convierta en evidencia de una u otra cosa: si se quita el último estrato de pobreza propuesto por el CT, entonces sólo el $54 \%$ de los mexicanos son pobres. Por otro lado, me da buenas razones para afirmar que una norma o un estándar depende, en gran medida, de fines y valores: el estándar utilizado por el CT obedece a una definición de pobreza, según la cual, las privaciones deben ser consideradas como tales, aun si no es posible eliminarlas de inmediato; por su parte, el estándar que utiliza el gobierno depende de un criterio según el cual la pobreza son aquellas carencias que las posibilidades del país le permiten enfrentar. Finalmente, el ejemplo en cuestión ilustra cómo los estándares (o normas) que sancionan nuestros procedimientos cognoscitivos o que guían nuestras elecciones y decisiones dependen de criterios que no necesariamente compartimos todos los seres humanos.

Estoy de acuerdo con Martínez en que la posibilidad de elegir entre estos estándares depende de normas de dependencia 
epistémica, esto es, de normas que están implícitas en nuestras prácticas cognoscitivas y que sancionan como racionales ciertas decisiones y creencias sobre la base de las creencias o las habilidades de otros. Desde mi punto de vista, la justificación de dichas normas proviene de una actitud crítica que si bien nos permite confiar en los estándares de ciertos especialistas, también nos lleva a confrontar puntos de vista diferentes. La comunidad pertinente (por ejemplo, la afectada por la decisión involucrada en la aplicación de la norma), con base en dicha actitud crítica, decidirá cuándo alguien es un experto, quién es el experto apropiado para sus fines y hasta qué punto está dispuesta a creerle y, así, validará la norma en cuestión.

Si lo anterior es correcto y si aceptamos, siguiendo a Martínez, que las reglas heurísticas no deben entenderse como meras disposiciones a responder de maneras específicas en circunstancias particulares, sino como la implementación concreta de procedimientos que se validan a través de procesos socialmente articulados en los que la información contextual y las prácticas de la cultura a la que pertenece el sujeto que las utiliza desempeñan un papel importante, entonces podemos aceptar que las reglas heurísticas pueden ser formuladas en términos de enunciados de permisividad epistémica. ${ }^{20}$ En este sentido, las reglas heurísticas son normativas. Martínez asevera:

la regla heurística no puede separarse de consideraciones normativas que puede ser que no sean formulables en términos de principios generales; tampoco es posible caracterizar el dominio de aplicación de la regla a través de un estudio de las circunstancias en las cuales el resultado de su aplicación es correcto o no. (Martínez 1999, p. 17)

El punto central es que las normas del razonamiento, o las reglas en que ellas se manifiestan, no necesariamente son $n i$

${ }^{20}$ De acuerdo con García un enunciado de permisividad epistémica establece, por ejemplo, lo siguiente: "Si $S$ cumple tales y tales condiciones, entonces está epistémicamente permitido que $S$ infiera tal creencia o estado intencional" (García 1999, p. 4). 
formales ni universales. Puede haber normas dependientes de contenido, que sólo sean aplicables en cierto dominio específico, pero que sancionen procesos cognoscitivos y que establezcan la manera como está epistémicamente permitido razonar en dicho dominio de conocimiento. Si lo que hasta aquí he argüido es correcto, entonces "ser racional" no puede restringirse al uso de un número determinado de principios de razonamiento, los cuales se establecen independientemente de cómo razonen de hecho los sujetos. En otras palabras, aquello que se requiere para considerar a un sujeto como agente racional es mucho menos de lo que suponen los defensores de las tesis de racionalidad e irracionalidad: para afirmar que alguien actúa racionalmente es suficiente que lo haga de acuerdo con el conjunto de prácticas cognoscitivas sancionadas en la comunidad a la que pertenece. Desde esta perspectiva, la información empírica acerca de las capacidades cognoscitivas de los sujetos y las limitaciones prácticas que las situaciones específicas imponen en nuestro razonamiento desempeñan un papel en el establecimiento de los requisitos que deben satisfacer los sujetos para ser considerados racionales.

Ahora bien, podemos suponer que un sujeto que tiene creencias razona conforme a ciertas reglas normativas y, si razona siguiéndolas, entonces necesariamente están en su competencia racional. Dichas reglas, en tanto que son normativas, son constitutivas del ideal al que todo sujeto debe aspirar o, en otras palabras, son constitutivas de la noción de racionalidad aplicable a un sujeto (García 1999). Así, las reglas que caracterizan apropiadamente lo que comúnmente llamamos "racionalidad" son también, parcialmente, constitutivas de nuestra competencia racional. Sin embargo, la posibilidad de caracterizar lo que significa "ser racional" no depende de coleccionar un número discreto de reglas extensionalmente caracterizables. Por las razones antes esgrimidas, considero que la manera en que de hecho somos racionales está más adecuadamente capturada por la idea de Martínez de que razonamos a través de procedimientos heurísticos que tienen lugar en un medio ambiente normativo. 
Un procedimiento heurístico es un "proceso de transformación de un sistema material que puede tener como consecuencia la implementación de una regla heurística" (Martínez 2003, p. 56). Estos procedimientos son el resultado de un sinnúmero de factores, entre los que se encuentran la información contextual y cultural y las prácticas cognoscitivas de la comunidad a la que pertenecemos; en este sentido, su individuación y su caracterización dependen de cómo se presenta la información, así como del contexto cognoscitivo en que está inmerso el sujeto que los utiliza, del medio ambiente en que se desarrolla y de las prácticas cognoscitivas vigentes en dicha comunidad. Un conjunto de procesos de esta naturaleza jerárquicamente organizados alrededor de la tarea de resolver cierto tipo de problema, de llevar a cabo una inferencia o un razonamiento cualquiera constituye lo que Martínez llama una "estructura heurística". Si aceptamos que la forma en que se estructuran los juicios en un área del conocimiento responde a las características recién mencionadas, entonces, podemos afirmar que nuestro razonamiento tiene una estructura heurística. Además, es posible aseverar que los procedimientos heurísticos a partir de los cuales se organiza y se estructura nuestro razonamiento tienen un componente normativo: más allá de que describan correctamente las maneras como razonamos, ellos nos dan una pauta para ser mejores agentes racionales y para razonar correctamente. Esto es, dichos procedimientos no sólo describen nuestra habilidad para razonar, sino que prescriben procesos cognoscitivos y, en este sentido, caracterizan, parcialmente, lo que significa "ser racional".

Si lo anterior es correcto y si aceptamos que existe una convergencia entre el concepto de racionalidad aplicable a los seres humanos y nuestra competencia racional, tomando esta última como un mecanismo subyacente que nos ayuda a entender los diferentes contextos y las soluciones posibles a los problemas planteados, de forma que podamos resolverlos racionalmente, entonces podremos afirmar que nuestro razonamiento tiene una estructura heurística, la cual refiere a una constelación de prácticas epistémicas que dan cuenta de lo que significa "ser racional". Así, es posible afirmar que la estructura heurística de 
nuestro razonamiento apunta a la manera como los seres humanos somos racionales y, en este sentido, razonar de acuerdo con dichas reglas implica razonar correctamente.

\section{Conclusión}

Los resultados obtenidos de una serie de experimentos en psicología cognoscitiva apuntan hacia la idea de que una teoría plausible de la racionalidad humana debe tomar en cuenta de qué maneras razonamos los seres humanos, el medio ambiente en que nos desarrollamos y, en general, el contexto cognoscitivo en que estamos inmersos para proponer un ideal que sirva tanto para evaluar la conducta cognoscitiva de los seres humanos, como para dar consejos de cómo ser mejores agentes racionales.

Las interpretaciones de los experimentos que han dado lugar a la tesis de irracionalidad y que han sustentado la de racionalidad llegan a conclusiones opuestas a partir de los mismos supuestos. Esto es posible porque una de las premisas cruciales que les permiten sostener sus propias conclusiones es aquella que refiere a cómo se explican los errores cometidos por los sujetos en las pruebas experimentales: la tesis de irracionalidad los explica como sesgos en nuestro razonamiento y la de racionalidad da cuenta de ellos en términos de errores de ejecución. Si aceptásemos que "ser racional" significa razonar, la mayor parte del tiempo, de acuerdo con los principios normativos del razonamiento correcto y estos últimos refieren a las reglas de la lógica y del cálculo de probabilidades, entonces tendríamos que aceptar el dilema al que ellas nos enfrentan: o bien los seres humanos razonan de acuerdo con dichos principios y, por tanto, son racionales; o bien razonan de acuerdo con reglas diferentes de las normativas y, por tanto, son irracionales.

Ahora bien, es posible evadir el dilema en cuestión, si se rechazan los supuestos antes mencionados. Gigerenzer ha hecho ver que el significado de "ser racional" no puede capturarse exclusivamente a través de la recopilación de un conjunto de reglas que provienen de nuestras intuiciones de lo que es un buen razonamiento y, en este sentido, que nuestra competencia racional no puede caracterizarse en función de la suma de reglas 
que de hecho usamos. Martínez, por su parte, ha defendido la idea de que aquello que caracteriza nuestra competencia de razonamiento es un conjunto de procedimientos heurísticos que nos permiten transformar un sistema material o conceptual en una posible solución a un problema y que sólo pueden individuarse en virtud del contexto y de la manera como se presenta la información.

Si aceptamos las ideas de estos autores y si aceptamos que las reglas que utilizamos para razonar no siempre son reglas formulables en términos de principios generales, entonces parecería muy poco plausible pretender reducir el estudio del razonamiento humano al estudio de unos cuantos principios claramente distinguibles. Además, si, como he argüido, las reglas heurísticas pueden formularse en términos de enunciados de permisividad epistémica, entonces razonar correctamente muchas veces implicará razonar de acuerdo con ellas. Si bien las reglas de la lógica y del cálculo de probabilidades desempeñan un papel normativo en nuestro razonamiento, razonar de acuerdo con ellas no es suficiente para razonar correctamente, ni razonar de acuerdo con reglas heurísticas implica razonar incorrectamente. En este sentido, el uso de reglas heurísticas apunta a la manera como somos racionales.

Esta última idea abre la puerta para desarrollar una teoría de la racionalidad acorde con las capacidades y limitaciones cognoscitivas de los seres humanos de carne y hueso. Si bien la evidencia arrojada en los experimentos aquí analizados no basta para rechazar los supuestos subyacentes en las tesis de racionalidad y de irracionalidad, sí nos ofrece buenas razones para cuestionarlos, y nos da elementos para defender la idea de que no tiene sentido pedirle a un sujeto que haga algo que no puede hacer para considerarlo racional. 


\section{BIBLIOGRAFÍA}

Boltvinik, Julio, 2002, "Verdad técnica y verdad oficial", La Jornada, viernes 16 de agosto, p. 22.

Cohen, Jonathan, 1986, The Dialogue of Reason, Clarendon Press, Oxford.

Chomsky, Noam, 1986, Knowledge of Language, Praeger, Nueva York.

Eraña, Ángeles, 2003, Normatividad epistémica y diversidad cognoscitiva, tesis doctoral, Universidad Nacional Autónoma de México.

Evans, Jonathan St.B.T., 1984, "Heuristic and Analytic Processes in Reasoning", British Journal of Psychology, no. 75, pp. 451-468.

García, Claudia Lorena, 1999, "Razonamiento heurístico y racionalidad", artículo presentado en el XIV Congreso Interamericano de Filosofía y X Congreso Nacional de Filosofía, Puebla, México.

Gigerenzer, Gerd, 2000, Adaptive Thinking, Oxford University Press, Oxford.

—_, 1992, "Discovery in Cognitive Psychology: New Tools Inspire New Theories", Science in Context, vol. 5, no. 2, pp. 329-350.

—_, 199la, "From Tools to Theories: A Heuristic Discovery in Cognitive Psychology", Psychological Review, vol. 98, no. 2, pp. 254-267.

Gigerenzer, Gerd, 1991b, "On Cognitive Illusions and Rationality", en Ellery Eells y Tomasz Maruszewski (comps.), Probability and Rationality, Studies on L. Jonathan Cohen's Philosophy of Science, Rodopi, Amsterdam/Atlanta, pp. 225-249.

- y Daniel G. Goldstein, 1996, "Reasoning the Fast and Frugal Way: Models of Bounded Rationality", Psychological Review, vol. 103, no. 4, pp. 650-670.

Goodman, Nelson, 1965, Fact, Fiction and Forecast, The BobbsMerrill Company, Nueva York.

Harman, Gilbert, 1988, Change in View, The MIT Press, Cambridge, Mass.

Lopes, Lola L., 1991, "The Rhethoric of Irrationality", Theory and Psychology, vol. 1, no. 1, pp. 65-82.

Macnamara, John, 1986, A Border Dispute, The MIT Press, Cambridge, Mass.

Martínez, Sergio F., 2003, Geografía de las prácticas científicas, Instituto de Investigaciones Filosóficas-UNAM, México 
Martínez, Sergio F., 1999, "La estructura social de la cognición", artículo presentado en el XIV Congreso Interamericano de Filosofía y X Congreso Nacional de Filosofía, Puebla, México.

Rips, L., 1984, "Reasoning as a Central Intellective Ability", en R.J. Sternberg (comp.), Advances in the Study of Human Intelligence, vol. 2, Erlbaum, Nueva Jersey, pp. 105-147.

Sober, Elliott, 1978, "Psychologism", Journal of Theory of Social Behaviour, vol. 8, no. 2, pp. 165-191.

Stanovich, Keith E. y Richard F. West, 2000, "Individual Differences in Reasoning: Implications for the Rationality Debate?", Behavioral and Brain Sciences, no. 23, pp. 645-726.

Stein, Edward, 1996, Without Good Reason, Clarendon Press, Oxford.

Tarski, Alfred, 1965, Introduction to Logic and to the Methodology of Deductive Sciences, Oxford University Press, Nueva York.

Tversky, Amos y Daniel Kahneman, 1982, "Judgment under Uncertainty: Heuristics and Biases", en Kahneman, Slovic y Tversky (comps.), Judgment under Uncertainty: Heuristics and Biases, Cambridge University Press, Cambridge.

Wason, Peter, 1966, "Reasoning", en Brian Foss (comp.), New Horizons in Psychology, Penguin, Harmondsworth.

— - y Philip Johnson-Laird, 1972, Psychology of Reasoning, Harvard University Press, Cambridge, Mass.

Recibido el 7 de julio de 2003; aceptado el 5 de noviembre de 2003. 